\title{
Cortázar-Heker (1978-1981). Polémica elidida/genocidio negado
}

\author{
Cortázar-Heker (1978-1981). Controversy \\ Elided/Genocide Denied
}

\begin{abstract}
Resumen
Abordo en este texto la conocida "polémica" entre Liliana Heker y Julio Cortázar desde una perspectiva poco transitada, ligada al análisis de los discursos sociales, con atención a las huellas dejadas en ellos por el genocidio de la desaparición forzada de personas llevado adelante por la dictadura cívico-militar argentina (1976-1983). Señalo como hipótesis de trabajo la imposibilidad de la polémica presentada por Heker, con base en el desgarro, bajo las condiciones contextuales citadas, del "contrato de lectura" prevaleciente en la interacción cultural de la izquierda latinoamericana y argentina durante las décadas de 1960-70 del siglo XX. Analizo las categorías "emoción/exageración", y algunos de sus términos asociados, como recurso crítico utilizado por Heker frente a determinadas afirmaciones de Cortázar. Busco así aproximar una reflexión crítica en torno a lo que denomino "genocidio negado" como condición aceptada en el discurso de Heker para llevar a cabo su "polémica".
\end{abstract}

Palabras claves

Cortázar, Heker, polémica, discurso social, contrato de lectura, genocidio negado

\begin{abstract}
I discuss in this text the well-known "controversy" between Liliana Heker and Julio Cortázar from a little traveled perspective, linked to the analysis of social discourses, with attention to the traces left in them by the genocide of the forced disappearance of people carried out by the civic dictatorship -Army military (1976-1983). I point out as a working hypothesis the impossibility of the controversy presented by Heker, based on the tear, under the conditions of the dictatorial context, of the prevailing "reading contract" in the cultural interaction of the
\end{abstract}


Latin American and Argentine left during the 1960s-70s. I analyze the "emotion/exaggeration" categories, and some of their associated terms, as a critical resource used by Heker against certain statements by Cortázar. I thus seek to approximate a critical reflection on what I call "genocide denied" as a condition accepted in Heker's speech to carry out his "controversy".

Keywords

Cortázar, Heker, controversy, social discourse, reading contract, genocide denied.

[...] cuando enmudezcan todas las voces, habrá todavía una, salvada por la distancia, que señale y condene, que denuncie y ayude, que movilice y congregue.

(Haroldo Conti, "Cuando enmudezcan todas las voces" 4)

Usted se emociona con su libertad.

(Liliana Heker, "Exilio y Literatura II” 5)

\section{Introducción}

Tras el golpe de estado de 1976 ocurrido en la Argentina, el escritor Julio Cortázar sumó su voz a la denuncia del régimen dictatorial a través de conferencias, artículos, relatos ficcionales, entrevistas y giras políticas por países europeos y latinoamericanos.

En tanto en Argentina, por regla general, se desconocían tales actividades de solidaridad y denuncia, o bien, sus referencias llegaban con años de atraso, algunas de sus intervenciones políticas, no obstante, suscitaron en el país, planteos polémicos en torno a sus concepciones sobre el exilio y sobre la práctica de un genocidio cultural por parte de los dictadores, militares y civiles, que habían tomado violentamente el poder.

Ese debate, que identificamos como "la polémica Heker-Cortázar", se extendió por años y dejó profundas huellas en la construcción del campo intelectual posdictatorial. Sus nudos centrales -más allá incluso de lo/as intelectuales que han 
participado de ella- representan ejes y perspectivas de análisis de la realidad aún presentes en la sociedad argentina.

Las trabajosas construcciones de memoria e identidad, en tanto ensayos culturales, colectivos, correspondientes a un determinado período, reconocen junto a la elección de temáticas privilegiadas, también privilegiados silencios (Pollak). Si bien la "polémica" Heker-Cortázar ha sido revisitada en distintos momentos de la posdictadura, involucrándose miradas críticas sustentadas en distintos intereses, generaciones y posturas políticas (Romano, Bayer, Ferrero, Giordano, Diego, Jensen); una perspectiva específica sobre las huellas de la desaparición como emblema del genocidio argentino (1976-1983), con sus metáforas de vacío, negación, olvido, silencio, no ha sido suficientemente dedicada al análisis de la emergencia y persistencia del citado debate.

El objetivo de este texto no es volver sobre lo ya tantas veces analizado respecto al tema del exilio, la posición de sujeto de Cortázar en ese espacio político, la apelación a una cartografía de intelectuales alejados del país o resistentes en él, sino analizar la incidencia en la trama textual protagonizada por Cortázar y Heker entre 1978 y 1981 de un asunto previo, en tanto causal de las denuncias antidictatoriales y las controversias intelectuales de período, como lo es la perpetración de un plan sistemático de exterminio sobre una amplia gama de grupos y personas opositoras al régimen dictatorial o cercanas a ellas (CONADEP, Duhalde). Considerando que ese plan adoptó una dimensión represiva nacional (y también regional) centrada en el arma de la desaparición forzada de personas a través del funcionamiento de cientos de centros clandestinos de detención, me pregunto por las huellas del genocidio cultural, devenido del plan de exterminio mencionado, en las prácticas intelectuales de esa etapa.

Si bien la definición jurídica de lo que configura la desaparición forzada recorta un claro objeto desde el punto de vista penal (ONU), diversas narrativas testimoniales, ficcionales, ensayísticas, entre otras, dan cuenta del modo en que la vivencia personal y colectiva de la desaparición forzada resulta en gran medida inasible y en parte, intransferible por su misma índole sustractiva -la negación de 
la vida y de la muerte de las personas apresadas-, de tal modo que sus efectos desaparecedores modelan, a través del terror, el vacío y la negación de sentido, las subjetividades sociales de los grupos expuestos a la aplicación de ese plan de aniquilamiento. En este aspecto, la negación del genocidio forma parte constitutiva de su acción desarticuladora en una doble faz: como discursividad y práctica de los perpetradores y como efecto sobre las subjetividades individuales y sociales a las que está dirigida (Gatti, Feierstein).

Desde esta perspectiva, pensar la dimensión del genocidio cultural, supone un ejercicio de desarmado de las consecuencias de esa transformación brutal de las relaciones sociales impuestas por los dictadores. Algo que Cortázar intentó tempranamente, en numerosas intervenciones públicas orales y escritas, parte de cuyas lecturas críticas procuramos recorrer aquí.

\section{Los textos del intercambio Cortázar-Heker}

El intercambio consta de cuatro tramos aparecidos, el primero de ellos -"América Latina, exilio y literatura" de Julio Cortázar- en la revista Eco de Colombia, en noviembre de $1978^{1}$, y los tres siguientes en la revista $E l$ Ornitorrinco, de Argentina: "Exilio y literatura. Polémica con Julio Cortázar", de Liliana Heker, fue publicado en la edición de enero/febrero de 1980, mientras que "Carta a una escritora argentina", de Cortázar, y "Respuesta de Liliana Heker", de esta autora, aparecieron en la edición de octubre/noviembre de 1981. Los extendidos y diferentes tiempos, en términos político-epocales, en que se desarrolla este intercambio -asunto tematizado por Cortázar en su Carta- si bien no serán tratados específicamente aquí, constituyen un marco contextual para el análisis que no debería soslayarse.

En el artículo de Eco, Cortázar centra su enfoque y su denuncia en el "genocidio cultural" que se extiende por varios países de América Latina -y en Argentina como parte de ella- sometidos a dictaduras y guerras contrainsurgentes;

${ }^{1}$ Todas las citas del artículo "América Latina, exilio y literatura" de Cortázar corresponden a la edición de Argentina: Años de alambradas culturales. Barcelona: Muchnik, 1984. 16-25. 
genocidio del cual el "exilio cultural" externo e interno es una de sus consecuencias políticas. Pretende alentar a los escritores a producir obras que reviertan los efectos del terror y la censura fortaleciéndose en la apuesta vital, "positiva" en sus palabras, de intentar sobreponerse al dolor y la distancia a través de un repertorio de recursos artísticos ligado al humor, la locura creativa y la invención literaria, en tanto opuestos a la tristeza, la racionalidad instrumental del aniquilamiento y a cierta literatura previsible, que adviene tras el sentimiento de frustración y desarraigo. Demarca así cuál es su punto de interés como intelectual latinoamericano en la encrucijada de las dictaduras que asolan la región: escribir y estimular a escribir un mejor libro que el que acaba de quemar el régimen. Aclara al inicio de su texto que su visión es parcial y recurre en algunos párrafos a su propia experiencia como escritor asumiéndose, para esta etapa, como un exiliado de la dictadura argentina.

El primer artículo de Heker define el intercambio como "polémica" y toma un aspecto de los varios que aborda Cortázar: la caracterización del exilio personal que asume el escritor a partir del golpe de estado de 1976, luego de residir voluntariamente en Francia desde 1951, así como la caracterización del exilio argentino en general (externo e interno) poniendo en entredicho la legitimidad de su palabra como (real) exiliado y como (real) conocedor de lo que acontece en el ámbito cultural local. Considera que Cortázar incurre en generalizaciones y exageraciones que dan en la dramatización de la situación de los escritores en el país e incluso fuera de él. Encuentra en el artículo de Eco una lectura afectiva y fatalista de lo que ocurre en Argentina, carente de eficacia histórica para revertir el estado de las cosas que se busca transformar.

El siguiente tramo del intercambio consta de la Carta que le envía Cortázar a Heker tras recibir su artículo de 1980, en la que centralmente argumenta su voluntad de no polemizar con la escritora en principio porque, a juzgar por el comienzo y el final de su artículo, entiende que la escritora "no tenía demasiadas críticas" que hacerle, pero sobre todo por la paradoja que ella le plantea "hablando de todo menos de lo que pone en marcha ese todo" (3). Alude así al recorte de temas esenciales a los que debe recurrir la autora para expresarse bajo la censura 
dictatorial y a su rechazo a escribir del mismo modo y con las mismas omisiones. Al final del texto la invita, a través de la metáfora de una escena de boxeo, a dirigir sus críticas "al referí", que decide e interviene por sobre quienes luchan en el ring.

Cierra la serie de réplicas, la respuesta de Heker a esa Carta en la que rechaza la decisión de Cortázar de no polemizar y retoma amplificadamente el eje del exilio personal del autor criticando la validez de sus argumentos para ocupar ese locus, y subrayando el desconocimiento -sobre todo vivencial- de lo que se realizaba entonces en el ámbito político-cultural argentino, bajo las condiciones de la censura y la persecución ${ }^{2}$.

\section{Objetivos y perspectiva de análisis}

Busco, entonces, en estas notas recorrer la tópica "polémica" iniciada por la escritora Liliana Heker desde una óptica algo diferente a la transitada por la crítica político-literaria. Como he señalado, no interesa en esta ocasión referir trayectorias y actitudes personales puestas en juego entonces por sendos autores, no al menos en tanto voces particulares; sino reconocer en su lectura la traza de ciertos discursos sociales emergentes en los textos de Heker y Cortázar -bien que desde espacialidades distintas y distantes- en el contexto de la dictadura cívicomilitar argentina. Para sostener esta perspectiva me valdré de las propuestas relativas al análisis del discurso social elaboradas por Marc Angenot, de cuyas ideas acerca de lo enunciable en un determinado contexto socio-histórico se nutre el marco teórico desde el que abordo estos intercambios textuales. Como desarrollaré más adelante, tres aspectos o dimensiones del corpus cobran interés analizados en contacto con los trabajos de este autor.

Un primer aspecto es el referido a la condiciones de posibilidad de una polémica entre Cortázar y Heker en el contexto dictatorial. Si tal como lo expone Angenot, "todo debate en la opinión 'pública' o en un sector dado, por ásperos que sean los desacuerdos, supone un acuerdo previo basado en el hecho de que el tema

\footnotetext{
2 Para un mayor detalle sobre lo argumentado en cada tramo de estos intercambios, v. Jensen (2005) y Ferraro (2007).
} 
'existe', que 'merece' ser debatido -y que un denominador común mínimo sirve de primer rango a los desacuerdos y a las polémicas." (1889 8), sostendré la imposibilidad de esa polémica en los términos planteados por la escritora al encontrarse dañado, de un modo que luego expondré, el "denominador común mínimo" que podría poner en diálogo, polémico, a ambos intelectuales.

Un segundo aspecto, desde luego relacionado con el anterior, consiste en los límites y permisos que los discursos sociales proveen a los emisores en determinados periodos. El orden de lo indecible se levanta por ausencia -pero no por ello, sin efectos- en los intersticios y los bordes del discurso social legitimado. En palabras del autor: "La función de los discursos sociales, función concomitante a sus monopolios de representación, es producir y fijar las credibilidades, las legitimidades, las validaciones, las publicidades (volver públicos los gustos, las opiniones, las informaciones, los valores). De modo complementario, le corresponde rechazar y censurar lo impensable.” (1889 8). Trabajaré desde esta visión los posibles significados de aquello que identifico como los silencios, las omisiones, las huellas del poder desaparecedor en el discurso social dominante de la época.

Finalmente, y también arista de un mismo asunto de dinámica complejidad, recuperaré para mi análisis la noción de hegemonía de Angenot entendida como la tendencia homogeneizante de los discursos sociales, incluso los contradictorios, de acuerdo a la tracción realizada por el amplio repertorio de prácticas, estilos, reglas, intervenciones interdiscursivas que construyen la legitimidad y la extensión de aquello que puede ser dicho en las disputas por el sentido puestas en juego socialmente según los contextos y períodos históricos.

En cada sociedad -con el peso de su "memoria" discursiva, la acumulación de signos y modelos producidos en el pasado para estados anteriores del orden social- la interacción de los discursos, los intereses que los sontienen y la necesidad de pensar colectivamente la novedad histórica producen la dominancia de ciertos hechos semióticos -de "forma" y de "contenido"- 
que sobredeterminan globalmente lo enunciable y privan de medios de enunciación a lo impensable o lo "aún no dicho" (que no se corresponde de ningún modo con lo inexistente o lo quimérico). (Discurso 29)

En este caso, y como contraparte de lo no dicho en cierto discurso social del período 1976-1983, me interesará inscribir los segmentos del intercambio HekerCortázar en una trama de textos y debates correspondientes a años anteriores y a situaciones políticas distintas a las que dan marco a esta "polémica", los cuales proyectarán sus argumentos y tópicos en el inédito escenario impuesto por la dictadura cívico-militar, donde la novedad histórica queda subsumida bajo el despliegue de un discurso aceptadamente pronunciable en tal escenario, por ya dicho y ya legitimado. Más adelante desarrollaré este tema.

Buscaré pues precisar la imposibilidad de la "polémica" planteada, no solamente a causa del intento de Cortázar de desactivar ese modo argumentativo en el intercambio con Heker, promoviendo de manera explícita la elusión del enfrentamiento verbal inter pares en el escenario público de la denuncia antidictatorial; sino a causa del desgarramiento político-social del contrato de lectura prevaleciente en años anteriores entre ambos escritores y, en general, en la sociabilidad de la cultura de izquierda latinoamericana, y particularmente, argentina, previa al golpe de estado del 24 de marzo de 1976 (Terán, Gilman). A la vez, me interesará ahondar en los factores que pudieran hallarse a la base del impulso que moviliza a Heker para polemizar con un antiguo aliado político y referente literario de su generación, en el momento en que éste pretende sostener una acción solidaria de impacto internacional para con la resistencia al régimen que está llevando a cabo un genocidio, apenas nombrado - por entonces- de ese modo.

La misma situación de desencuentro o desfasaje entre ambas posiciones da cuenta de la profundidad de la ruptura de aquel contrato, en tanto los actores -los discursos sociales que esgrimen- no logran alcanzar una síntesis ni aún, una unidad en la contradicción que tendiera a respetar la diversidad de miradas en una alianza común; sino que tales discursos proyectan, aumentadas, sus posibles fallas, 
duplicando el desencuentro donde se pretende aminorarlo -en un caso- y secundarizando el crimen mayor que envuelve a la sociedad argentina bajo la dictadura, en el otro. Trabajaré también aquí con las categorías emoción/exageración, y algunos de sus términos asociados, como recurso crítico reiterado en las exposiciones de Heker frente a determinadas afirmaciones de Cortázar. Buscaré con ese análisis aproximar una reflexión crítica en torno a lo que denomino genocidio negado como condición aceptada en el discurso de Heker para llevar a cabo su "polémica".

\section{Debate inventado/polémica elidida}

Una precisión inicial resulta necesaria como parte de nuestra hipótesis de trabajo: si bien la secuencia de textos y respuestas comienza con un primer artículo de Cortázar publicado en 1978, la "polémica" misma se inicia con la réplica de Heker, publicada dos años después en El Ornitorrinco (enero-febrero de1980). Esta revista fue parte inescindible de la construcción polémica presentada a Cortázar. Ubicada por alguno/as autores como una de las expresiones de la resistencia cultural bajo la dictadura (Calabrese, Romano, Saítta), sus referentes, Abelardo Castillo y la misma Liliana Heker, traían consigo una extensa trayectoria en revistas literarias ligadas, en sentido amplio, al universo cultural de la izquierda latinoamericana de fines de los años 50 en adelante y hasta la irrupción del golpe de estado de 1976. Tanto El grillo de papel como El escarabajo de oro abrieron espacios polémicos, de creciente intensidad en los marcos de disputa políticocultural de esos años.

A pesar, entonces, de que desde un punto de vista cronológico es Cortázar quien inaugura de algún modo la secuencia, elijo invertir el orden de presentación en que ambos escritores abordan ciertos temas críticos y los ponen en discusión, dado que quien lleva adelante el propósito de polemizar es Liliana Heker, en tanto Cortázar busca elidir ese flanco de conflicto con diversas estrategias desplegadas en su Carta, tanto como a través de su definido silencio, tras el segundo texto de Heker. 
Podría pensarse que siempre hay un primer término en un debate, y que el mismo arranca, verdaderamente, en ese segundo tiempo que abre la respuesta o la crítica a esos textos iniciales. También es claro que toda polémica debe llegar a su fin, al menos, provisoriamente. Sin embargo, la noción de una polémica que, en este caso, sólo cuenta con una parte contendiente, mientras la otra expresa su negativa a polemizar, me parece sugerente en cuanto a las condiciones de producción de tal intercambio, unas condiciones que, por un lado, son parte del argumento central de Cortázar en su artículo de la revista Eco y que a la vez, como tema también elidido en la polemista Heker, revierte en la negativa de Cortázar a aceptar los términos en que la escritora plantea sus críticas, vale decir, que revierte en la negativa a polemizar. Trataré de exponer, en el curso de este trabajo, la idea de una polémica que no fue, más allá o más acá de que, en algunas de las críticas culturales aquí relevadas, se ha considerado que no debió haber sido, y de que el registro empírico -sustentado en los artículos y revistas referidos y en la prolífica producción crítica que ellos despertaron y despiertan hasta el presente- pareciera demostrar que sí existió como tal, es decir, como polémica.

Tres son las dimensiones de la elisión, entonces: la de la forma polémica, en la voz de Cortázar, la de cierto nudo problemático central al tema en tratamiento en la voz de Heker, y una tercera elisión que estoy proponiendo como punto de partida para el análisis y que consiste en pensar la imposibilidad objetiva de esa "polémica" en el contexto del genocidio de la última dictadura argentina.

Es Diego quien señala la existencia de dos grandes “polémicas” desplegadas durante el período dictatorial 1976-1983 y la temprana posdictadura. En rigor, las "dos polémicas" vienen a representar etapas de un mismo debate referido éste a "los que se fueron" y "los que se quedaron"; desarrollado por un lado, en el tramo Cortázar-Heker (1978-1981) -primera polémica- y por otro, en el tramo Gregorich-

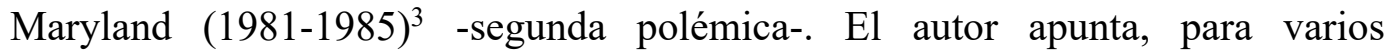
intelectuales hacia el inicio del período democrático,

${ }^{3}$ Convocado por Saúl Sosnowski, los días 2, 3 y 4 de diciembre de 1984, se llevó a cabo en la Universidad de Maryland un encuentro de intelectuales argentino/as, destinado a acercar 
la necesidad de cerrar el debate, de plantear el dilema como falso, y de recomponer un campo intelectual que, como decía Beatriz Sarlo, se encontraba "doblemente fracturado". La estrategia más recurrente para cerrar el debate fue la de cambiar la línea divisoria: la oposición no debe pensarse entre quienes se quedaron y quienes se fueron, sino entre quienes colaboraron y quienes resistieron. (195)

Reseña, además, las voces de escritores exiliados que al inicio de la posdictadura dan cuenta de su rechazo a los términos de este debate, como las de Héctor Tizón, Pedro Orgambide, Humberto Constantini. Este último es quien más explícitamente adhiere a la idea de una "polémica inventada", con comienzo en el primer artículo de Heker:

Ese conflicto fue creado artificialmente por un grupúsculo de escritores que, siendo benévolo, diría que fue inconsciente cuando lo expresó. Es cierto que estamos separados, o que hay una barrera de desconocimiento que no es fácil vencer, pero acentuar esa diferencia, inventar una polémica, me parece siniestro. Entonces, la actitud decente en estos casos no es inventar polémicas sino establecer puentes[...]. (196)

"Establecer puentes" entre la diáspora latinoamericana y la resistencia interior a las dictaduras de la región parece haber sido la motivación de fondo de varios artículos de Cortázar publicados en el exterior del país, durante el período dictatorial, y reunidos muchos de ellos en el libro Argentina: Años de alambradas culturales, preparado por el autor y publicado en 1984, después de su muerte; sin

posiciones entre quienes pocos años antes, desde el exilio o desde su residencia en el país, habían polemizado sobre temas relacionados con la dictadura que acababa de finalizar. El encuentro también se proponía debatir cuestiones futuras del ámbito cultural en el marco de la incipiente democracia, sin embargo el debate sobre las responsabilidades civiles en el pasado reciente dominó las intervenciones y discusiones, y reprodujo, en parte, las diferencias de orden éticopolítico planteadas en el contexto dictatorial (Sosnowski). 
embargo, no fue esa intención solidaria la recuperada por Heker para abrir paso a un posicionamiento crítico sobre el nudoso tema de los intelectuales y la dictadura de 1976.

¿Qué ocurrió, entonces, para que esa mano tendida, aun con sus factibles errores de visión respecto a una cotidianidad no vivida o sus diversas interpretaciones sobre el rol intelectual en un período signado por atroces violaciones a los derechos humanos, despertara rechazo en lugar de identificación o apoyo? Esta pregunta estimula y guía nuestro trabajo en la actual etapa de investigación.

A partir de la noción de "extratexto" de Yuri Lotman, Andrés Avellaneda en El habla de la ideología pone en relación la intersección de un discurso literario y otro no literario, a los que denomina respectivamente "serie literaria" y "serie social". La dinámica interactiva entre ambas series dará otras dos nociones relevantes para nuestro análisis, esta vez tomadas de Terry Eagleton, la de "código de identificación" y la de “contrato de lectura". La tensión entre lo dicho, lo aludido y lo callado -aspectos claves del discurso que conforman un determinado contrato de lectura-, nos permitirá enfocar en estos textos la relación posible entre la "polémica inventada", la polémica elidida y la eventual dilución del contrato de lectura entre ambos escritores.

Cortázar se propone decir (denunciar) contra el terror y la censura, busca para ello preservar cierto código de identificación -el de la libertad de pensamiento y la responsabilidad de acción frente a las injusticias, con "las armas de la literatura", como lo anticipaba en el reportaje que Alberto Carbone le realizó para la revista Crisis en 1973- conservando el objeto principal de su denuncia como eje (las violaciones perpetradas por las dictaduras, el genocidio cultural en Argentina, el papel de los exiliados en su repudio), protegido -al menos en primera instanciapor su residencia fuera del país. Heker, en tanto, espera suplir lo no dicho en sus artículos por causa del riesgo que correría al explicitarlo viviendo y actuando en la Argentina, con las competencias previsibles de lo/as lectores, por sobre el terror y la censura. En el repaso de los artículos de Heker pueden leerse determinadas 
referencias que tienden a situar su palabra en un cierto contexto, evitando la nominación de los aspectos más violentos del régimen dictatorial, así como del clima político-social en que se desarrolla la vida cotidiana, todo ello en el entendimiento de que no hace falta más para activar el código de identificación, al tiempo que se presupone -ya en código- que tampoco es posible decir más. Así, leemos: “...en épocas culturales como las que estamos viviendo” (Exilio 3), "ya refiriéndose a los últimos años” (4), "ya sabemos que no estamos en el mejor de los mundos" (5), "es precisamente en épocas como éstas..." (Respuesta 7), "cuando se juzgue históricamente la literatura de esta época" (7), "quienes hemos vivido desde dentro este proceso argentino" (7).

Sin embargo, al polemizar con Cortázar -cuyo contendiente es, en sus palabras, "la Junta"- ese contrato de lectura se descubre enrarecido: algo se ha roto pero no está claro aún su alcance, y las mismas palabras que antes podían despertar polémica en el mejor de los sentidos, como lo evidencia una activa producción crítica que tuvo, entre otros espacios intelectuales, a las revistas El grillo de papel y El escarabajo de oro como campo preferido de debate (Blanco) -de las que Heker junto a Abelardo Castillo han sido animadores- ahora se tornan vacuas, parecen ahondar no exactamente la disputa argumental, sino la ininteligibilidad de sus mutuas posturas. Si en la propuesta de Eagleton, lo que en un discurso "no se dice", es posible de ser "completado" con el código de identificación sostenido en determinada lectura, estrategia en la que parece confiar Heker a través de lo que denomina "la sutileza" (Respuesta 7), no es menos cierto -sobre todo en el contexto dictatorial- que, a la vez, ese no decir, calla, reafirma un estado de silencio, elide lo “central" (Carta 4); camino que por su parte, Cortázar no admite para sí; para su situación de libertad, al menos relativa frente al mapa represivo que atraviesa a América Latina y particularmente, a la Argentina. ${ }^{4}$

\footnotetext{
${ }^{4}$ Algunas afirmaciones respecto de las actitudes de Cortázar frente a la dictadura argentina de 1976 lo ubican en el lugar de la precaución o el autocuidado; tal el relato de Osvaldo Bayer en la película de Montes Bradley del año 2002, de Heker en los artículos que estamos releyendo, e indirectamente, de Castillo en sus crónicas del Mundial de Fútbol 1978 para el diario La Opinión. Menos visitado por la crítica resulta el viaje clandestino realizado por Cortázar en marzo de 1976 al archipiélago de Solentiname, a través del Lago de Nicaragua, todavía lejos de la victoria
} 
Toda paradoja se inscribe en la esfera de influencia de una doxa. Un debate solo se desarrolla apoyándose en una tópica común a los argumentos opuestos. En toda sociedad, la masa de discursos -divergentes y antagónicos- engendra un decible global más allá del cual solo es posible percibir por anacronismo el 'noch-nicht Gesagtes', lo aun no-dicho [...]. (Angenot, Discurso 28) [Énfasis en el original]

El modo en que Angenot piensa la dinámica interdiscursiva y las condiciones de producción de las polémicas nos invita a considerar la trama del discurso social prevaleciente en la etapa dictatorial como un decible cuya envolvente uniformidad, exhibe no obstante -en los silencios, en las imposibilidades- el desgarro de otros planos de entendimiento y de lazo social. Con relación a nuestro corpus, una tópica común se ha desvanecido o fracturado impidiendo la forma polémica, aun en el curso de su intento. Escribe Cortázar: "En vez de denunciar la causa central de ese exilio (ya sé que no podés hacerlo, pero entonces no habría que tocar el tema públicamente y con fines polémicos) [...]" (Carta, 4). Si existía anteriormente una plataforma posible de intercambio, de inteligibilidad, ya no resulta evidente para los discursos enfrentados. Una visión anclada en las condiciones socio-históricas anteriores al genocidio cultural puede reconocer en la secuencia de estos textos un código pre-argumental compartido; sin

sandinista de 1979 y muy próxima al arrasamiento por parte de la Guardia Nacional de Somoza, de la comunidad artístico-religiosa creada por Ernesto Cardenal; hecho ocurrido en octubre de 1977, y anticipado de algún modo por el escritor a través del relato Apocalipsis en Solentiname, el cual -junto al cuento Segunda vez- motivó la censura del régimen dictatorial argentino de su libro Alguien que anda por ahí. Otro aspecto no siempre calibrado por la crítica en cuanto a los riesgos asumidos por el escritor en defensa de sus convicciones lo representa la serie de amenazas recibidas en su casa de París, a través de su buzón de correos, presumiblemente realizadas por represores de la ESMA que se asentaron en esa ciudad, bajo la cobertura del "Centro Piloto de París", destinado a infiltrar los grupos de resistencia de lo/as exiliado/as latinoamericano/as, de los que participaba activamente Cortázar. Las acciones delictivas (secuestros, atentados, amenazas y homicidios) atribuidas a estos marinos de la ESMA continúan siendo investigadas en Francia por la abogada Sophie Thonon. [Comunicación personal, París, 2 abril 2016]. V. Lejtman, Román. "Centro Piloto. Massera en París". Documenta (2 julio 2006). https://www.youtube.com/watch?v=u-Pjasch09I. 22 agosto 2019. 
embargo, uno de los emisores expresamente rechaza dar el debate y en algo que llama "carta", se corre, amplía el foco, invita a polemizar en otra dirección, ¿pervive, entonces, el código común?

Tal como Avellaneda elabora las nociones de "asimilación" (del impacto de nuevas circunstancias históricas) y "réplica" (sobre todo a partir del "lenguaje mediato y traslaticio" propio de la literatura) para algunos intelectuales en relación con el surgimiento del peronismo (Habla 38), propongo un ejercicio similar para nuestro tema. Pensando esta amalgama de debate y silencio brindada por Heker y esa otra, de elisión de la polémica y denuncia entregada por Cortázar, podríamos considerar la existencia de una cierta asimilación de los códigos dictatoriales, por parte de Heker -así como una mediana rebeldía, ya que busca polemizar aun cuando no puede llevar a fondo ese propósito, y a través de esa contienda asimilada, pasar una cierta réplica al régimen, aunque mediatizada por la figura y la voz rebatida de Cortázar-. No obstante, el punto más crítico de esta decisión resulta el polemizar con un posible (y antiguo) aliado y no con quien figura en el centro de toda consideración argumental respecto de exilios, persecuciones, crímenes, censuras. En tanto Cortázar intenta hacer valer lo absurdo de esa empresa, corriéndose del lugar de la polémica, aunque no así de la réplica a la réplica. Esta decisión discursiva lo muestra entramado a y entramando a la vez una estela de desencuentros de largo aliento, inimaginables por su profundidad bajo las condiciones del anterior contrato de lectura, respecto del cual, si bien el escritor avista que esas condiciones han cambiado, tampoco logra comprender a fondo la envergadura de esos cambios.

Esto se hace legible cuando en su Carta a una escritora argentina previene que no habrá "sillas rotas, tirones de camiseta", pero que "buscaremos la verdad, tan lejos el uno del otro en el espacio pero desde un terreno común que, lo sé de sobra, compartimos y queremos" (3). Cortázar cree que el contrato de lectura que por años compartió con sus pares y que habilitó tanto el intercambio de colaboraciones literarias como de polémicas y críticas y, fundamentalmente, se sostuvo en la común noción de un sistema de injusticias a combatir, permanece 
intacto, o al menos quiere creerlo y por eso lo enuncia como una reposición del código compartido, del piso común desde el cual los debates son posibles, por más antagonismos que los invadan (Angenot). Sin embargo, lo que encuentra en la contra-respuesta de Heker es una fisura notable y superior a la constatada en el primer artículo de la escritora para esta serie.

Ahora bien, ¿qué contrato de lectura era posible en pleno estado de terror y censura? ¿Qué relaciones podía guardar con los contratos previos y verificables entre los mundos culturales y literarios de ambos autores? ¿Qué lecturas podían esperar unos y otros productores de textos en el presente dictatorial? ¿Cuáles eran las posibilidades y los límites de la forma polémica inter pares en ese contexto?

Si siguiéramos los flujos de esta situación discursiva, advertiríamos con mayor claridad la imposibilidad fáctica de la pretendida polémica: Heker asimila los códigos dictatoriales cifrados en la censura/autocensura y es a partir de esta asimilación que establece su réplica hacia una dirección diversa a la que supone el origen de la represión/censura, buscando debatir con el escritor las variaciones del exilio y sus posibles redefiniciones. Cortázar rechaza la asimilación del código dictatorial bajo el resguardo de su residencia en el exterior, y lo sitúa como blanco a combatir. No busca polemizar con lo/as exiliado/as externo/s ni interno/as, sino alentar sus fuerzas para enfrentar las dictaduras y producir, pese a las persecuciones y la distancia; de este modo, elide la polémica, aunque no deja por ello de “contestar".

Otro aspecto de la discusión sobre la existencia o no de una "polémica" entre Heker y Cortázar ha sido tratada por Alberto Giordano bajo el rótulo de la “denegación de la polémica” por parte de Cortázar, con una fuerte intervención teórico-política contraria a las posiciones del escritor. Si bien coincidimos en la evidencia de un corrimiento, rechazo o inhabilitación de la polémica en Cortázar, nuestros enfoques difieren en el recorrido descripto para seguir ese proceso. Giordano ubica a Cortázar en un sitial narcisista y deriva de allí toda la secuencia tanto de esta "polémica", como del conjunto de sus posicionamientos políticos, basado en una reflexión del crítico uruguayo Ángel Rama, anotada en su diario 
personal, a saber: la necesidad de promocionarse del autor argentino detrás de sus adhesiones a causas revolucionarias o antidictatoriales. Narcisismo y denegación es la síntesis que alcanza Giordano para nuestro tema respecto de Cortázar, en tanto Heker ocupa el lugar de la escritora que rompe el podio del intelectual consagrado, establece argumentos, desafía el paternalismo, si bien recurriendo a algún nivel de agresividad para con el autor admirado a la par que impugnado. Llamativamente, el contexto dictatorial que es ya texto abierto, ya texto encubierto en la "polémica" -explicitado por él, retaceado por ella, por motivos antes comentados- no figura en la crítica de Giordano; en su trabajo, que trata acerca de una denegación, lo que se desconoce es que las polémicas no se dan en el vacío, sino a través y como parte de un proceso histórico, entre tramas discursivas preexistentes y fuerzas sociales en pugna. Esta ausencia contextual en la perspectiva de Giordano no resulta anecdótica sino central al tema de nuestro trabajo, ¿por qué en el siglo XXI sigue siendo atractiva la reflexión en torno a las subjetividades de los autores que esta "polémica" puso en juego y, en cambio, conserva un segundo plano aquello que los llevó a expresarse y debatir? Más adelante volveré sobre esta particular denegación. Señala Giordano:

Lanzado al mundo para cumplir con dedicación y generosidad con los imperativos morales que le prescriben, en tanto intelectual, las causas revolucionarias a las que ha adherido, por un efecto que parecería paradójico, Cortázar se va encerrando cada vez más, sin saberlo, en la celebración narcisista de su figura de escritor comprometido. (38)

De sus numerosos textos de denuncia, ficcionales o no, sobre los crímenes de las dictaduras del Cono Sur, importan los motivos personalísimos que ellos ocultan. Es, ciertamente, un modo de lectura. Pero una mirada crítica sobre ese modo de leer abre el enfoque hacia otras circunstancias a ser consideradas. El calificativo narcisista cumple una función de encierro, en verdad notable, hacia quien se lo aplica, ya que cualquier actitud asumida remitirá a aspectos más o menos 
solapados de ese narcisismo. En esa línea, negarse a polemizar -ya nos fue demostrado por el crítico-, deviene narcisista y autoritario; aceptar las críticas y reconfigurar la propia visión en base a ellas, roza otro filón del narcisismo, ya que puede ser leído como afán de agradar y otra vez, no polemizar, y por lo tanto, nuevamente, cultivar el narcisismo; si en cambio, confronta y argumenta en abierta polémica: narcisista, autoritario, violento, el que no acepta las críticas ${ }^{5}$. En definitiva, la categoría narcisismo no aclara ni aporta para nuestro trabajo, sólo conmina a quien recibe esa calificación a un predeterminado encierro conceptual. Parece más acertado considerar una base narcisista en todo/a creador/a, la que respalda, a conciencia o no, su exposición pública; narcisismo que puede exacerbarse o acotarse en situación de polémica, según recursos y objetivos, y que impregna, a la vez, a lo/as distinto/as actores que la llevan adelante.

\section{Daño y elisión en contexto}

¿Cuál sería el contrato de lectura que, afirmo, resulta dañado en la contemporaneidad de esa no polémica, cuya elisión pone de manifiesto el daño sufrido?

Sería extenso desentrañarlo aquí, solo apunto algunos componentes identificables como propios de un mundo compartido, entre el compromiso sartreano de los intelectuales y la adhesión a los procesos revolucionarios y anticoloniales de América Latina y otras regiones del planeta. Ellos son: el combatir

${ }^{5}$ Respecto de la no aceptación por parte de Cortázar de las críticas a su obra y/o posturas públicas, vale recordar las intervenciones autocríticas de Cortázar respecto a temas como su interpretación política del peronismo entre 1945 y 1955 o las figuras machistas que articulan, en parte, su obra Rayuela. Sobre el primer tema es conocido su devenir autocrítico, sobre el segundo éste ha sido menos difundido. Véase, por ejemplo, la siguiente reflexión: "Cuando escribí Rayuela yo era tan machista como cualquiera de los otros latinoamericanos, el sentido crítico de esto me ha venido después. Si lo hubiera tenido en ese momento, jamás hubiera utilizado la expresión lector-hembra para designar a un lector pasivo. Y además fui muy duramente castigado por eso, es el momento de hacer la verdadera autocrítica...porque cuando empecé a recibir una correspondencia muy nutrida con respecto a Rayuela, descubrí que una gran mayoría de lectores eran mujeres; eran mujeres que habían leído Rayuela con gran sentido crítico, atacándola o aprobándola, pero de ninguna manera con una actitud pasiva, con una actitud de lector-hembra; es decir que eran lectoras, pero no tenían nada de hembras en el sentido peyorativo que el macho tradicional le da a la palabra hembra. Bueno, yo creo que éste es un problema que ya hemos dejado atrás y que es un vocabulario ya terminado." (Chao, 4'). 
con las armas intelectuales y creativas de que se dispone un orden injusto $\mathrm{y}$ crecientemente represivo a nivel mundial, regional y nacional, el avenirse al debate inter pares, el ejercer la crítica aún en el propio campo político-cultural, el defender las libertades creativas y el compromiso político a un mismo tiempo, el discutir sus límites y experimentar sus eventuales transgresiones.

Señalo que, al momento de plantearse la "polémica" por parte de Heker -que con espontaneidad esgrime los supuestos de ese contrato vigente entre fines de los 50 y mediados de los 70, del que han participado la autora y Cortázar, junto a otros actores del campo cultural latinoamericano y argentino-, ese contrato se encuentra dañado, enrarecido, roto. Sin embargo, no han sido ellos, en un inicio, quienes lo han desgarrado, sino el propio proceso genocida que se despliega entonces con toda su crueldad e insidia, y los alcanza -como a millones de personas-, bien que de modos diversos, siendo también tal proceso diferencialmente percibido, incorporado y/o contestado por los distintos sujetos sociales e individuales. Entre las nebulosas del método represivo aplicado por la dictadura la desaparición forzada de personas, el establecimiento de cientos de centros clandestinos de detención, tortura y exterminio- y la opacidad que toda realidad supone, algo superlativo y diferente está sucediendo. Cortázar lo advierte y solicita a su polemista la suspensión del combate entre los boxeadores para atender al árbitro que con su intervención, no los deja pelear (polemizar) como desearían. Mientras que Heker secundariza (por fuerza, se dirá) las palabras que nombran el estado de terror, haciendo prevalecer las antiguas reglas del enfrentamiento intelectual inter pares, como si el genocidio no hubiera impactado enteramente sus vidas; también sus contratos de lectura, también el sentido de sus debates.

La estrategia de omisión del genocidio resulta el envés del reproche acerca de la "exageración", atribuida por Heker a Cortázar; enseguida analizaremos este punto, pero antes me gustaría precisar lo que la posición de sujeto de la escritora en esta "polémica" está evidenciando como trama de un discurso y una práctica social generalizada localmente en el contexto del genocidio. Aunque Heker exprese en contra-respuesta a Cortázar que no es necesario que le cuente lo que pasaba en el 
país en 1978 porque "ella estaba en la Argentina" (Respuesta, 7), hay algo del orden desaparecedor de este genocidio que Heker -como amplios sectores sociales- no logra advertir como problema, como eventual insondable, inmersa como está en pleno estado de terror. Algo que, no obstante el paso del tiempo y los cambios institucionales ocurridos en la Argentina, continuará sin ver por muchos años en la posdictadura e incluso después, reeditando y respaldando en nuevos contextos las piezas de la así llamada "polémica Cortázar-Heker".

\section{La trama de textos previos en que se inscribe la "polémica"}

A partir del concepto de "intertexto" y la consideración general del carácter no unitario del discurso (Maingueneau), podemos analizar la presencia de textos previos, conformados por críticas literarias, entrevistas y debates, en el intercambio Heker-Cortázar. Habida cuenta de que ningún discurso parte de un punto cero de sentidos o tradiciones, nos interesa aquí relevar la trama discursiva que sostuvo dicha "polémica", particularmente, la identificación de aquellos discursos que provenían de la experiencia cultural anterior al golpe de estado de 1976. En este sentido, el texto no sería una elección libre sino "el producto de un trabajo sobre textos anteriores o contemporáneos" (139), nutrido de relaciones intertexuales variadas como la polémica misma o el comentario, entre otras. Buscaré delimitar en este punto, de qué modo los cuestionamientos previos dirigidos a Cortázar, desde diversas posturas estéticas y políticas, y respondidos por éste en una dinámica intelectual inmersa en el clima histórico de los años '60 y '70 del siglo XX, fueron puestos en juego en el curso de la "polémica" Heker-Cortázar, es decir, en plena consumación del genocidio de la última dictadura, sin tomar en cuenta los cambios de contexto. Algunos de los tópicos de dichos cuestionamientos refieren a la tensión entre el compromiso político y su expresión (o no) en textos literarios, la residencia en Francia y su vinculación activa con los procesos revolucionarios latinoamericanos, y la consecuente escisión "cuerpo/espíritu", desarrollo este último realizado por David Viñas. 
La figura óptica de la "remanencia retiniana", que sobreimprime imágenes secuenciales creando el efecto de interconexión, es adoptada por Angenot para señalar una particular interacción ya apuntada por Bajtin, por la que los "géneros y los discursos no forman complejos recíprocamente impermeables" (Discurso 25). El autor denomina "interlegibilidad" a este carácter poroso de los discursos, y adelanta:

La interlegibilidad asegura una entropía hermenéutica que hace leer los textos de una época (y los de la memoria cultural) con cierta estrechez monosémica, que escotomiza la naturaleza heterológica de ciertos escritos, anula lo inesperado y reduce lo nuevo a lo previsible. Las "nuevas ideas" corren el riesgo de pasar inadvertidas porque se abordan en un marco preconstituido que desdibuja aquello que se presta a una lectura "diferente". (26)

Esta noción de entropía, vinculada a otro término teórico de Angenot como lo es el de "hegemonía", ya mencionado, resulta interesante para describir, desde cierto punto de vista, el "encierro" de Cortázar por parte de Heker, en una lectura antigua de sus intervenciones, ligada a su exterioridad física y su eventual ajenidad cultural, la cual pudo provocar el efecto de impedir la visualización de lo "nuevo" en el discurso y los actos cortazarianos, esto es, su autoproclamación como exiliado ya no voluntario, en tanto estrategia de denuncia de la dictadura y de empatía con lo/as perseguido/as del régimen, un poco en el papel pre adjudicado por Haroldo Conti en 1974, de hablar cuando ya no quedaran voces. Esa empatía sería "la necesidad a ultranza de hacer causa común con los exiliados" (Exilio 3) que Heker rechaza al considerar que reedita la mencionada escisión cuerpo/espíritu, sin advertir en lo profundo de dicho discurso, que el genocidio en desarrollo creaba un nuevo escenario de fracturas y dispersiones, el cual, en términos de sobrevida y diáspora, alcanza incluso a los intelectuales que cuestionaban en Cortázar la actitud 
de tener su "espíritu” en América Latina, con sus conflictos, y su “cuerpo" en París, con sus comodidades.

Respecto de lo "nuevo" introducido por la dictadura en la trama de relaciones sociales, que no llega a advertirse en su calidad de distinto y hasta excepcional (Agamben) por los mismos actores que lo padecen, volveré en el siguiente apartado. Por el momento, apunto la reflexión de Diego respecto a las continuidades que encuentra en la "polémica" Heker-Cortázar, aunque éste las coloca en otra secuencia interpretativa, distinta a la que busco exponer aquí. Afirma Diego:

el triunfalismo del discurso setentista ha dado lugar, diez años después, a las polémicas sobre las responsabilidades de la derrota. En ambos casos, proliferan los argumentos ad hominem, pero cambia la pregunta: de "¿qué estás haciendo por la revolución?” a “¿qué estuviste haciendo durante la dictadura?". Sin embargo, nuevamente se plantea aquí la tensión entre ruptura y continuidad: aunque el debate es otro, aparecen en el segundo tópicos argumentales del primero. Por ejemplo, si se lee con atención la tan citada polémica entre Julio Cortázar y Liliana Heker, publicada en El Ornitorrinco, se advierte una continuidad de las líneas argumentativas: si Cortázar es un exiliado ahora político, no lo era antes, ya que su exilio era voluntario, de manera que si antes había desertado de la lucha, ¿por qué ahora va a liderar la resistencia desde afuera? (123) [Énfasis en el original]

Y más adelante, al abordar los editoriales de El Ornitorrinco, el autor introduce la noción de "anacronismo" para referirse a las posturas de la revista y de Abelardo Castillo, en particular, respecto de la referencia al compromiso sartreano de las décadas anteriores, puesta a significar en el período dictatorial. 
En términos generales, considera anacronismo y continuidad no del todo pertinente a rasgos discursivos presentes en Castillo, que desde nuestro punto de vista, también podríamos identificar, con sus giros de lenguaje específicos, en las posturas expresadas por Cortázar; sin embargo, en el análisis crítico del autor, solo Heker y Castillo se ven asimilados al "discurso setentista" de manera explícita. Sobre Cortázar, en cambio, prevalece una línea de fuga sutil que, a los efectos de nuestro trabajo, no permite observar el conjunto de la polémica inventada/elidida, solapando de modo inadvertido uno de los núcleos de nuestro enfoque que remite a la cadena de vacíos y silencios registrada tanto en la dictadura como en la posdictadura.

En otras palabras, el contrato de lectura se evidencia roto no por el abandono de Cortázar de cierta perspectiva emancipatoria propia de los años ' 60 y '70 del siglo XX - de hecho el autor imagina una salida revolucionaria para la dictadura de Videla y sus sucesores al mencionar que ésta terminará como la de "Batista" y "Somoza" (Carta 3)-, sino a causa de la prevalencia, en la decisión de Heker, de la polémica inter pares por sobre el enfrentamiento explícito con los representantes de la dictadura.

\section{Genocidio y exageración}

Parte de la línea argumental expresada por Heker en los artículos de esta serie recorre un conjunto de ideas vinculadas a dos términos: la "emoción" (como opuesta a la racionalidad) y la "exageración" (como subproducto emocional exacerbado). De este modo, Cortázar apela a la emotividad y no a la razón. Cortázar exagera.

Ya en el inicio de su primer artículo, elípticamente, aloja al escritor en la emoción, y a ésta entre los obstáculos para aprehender la realidad:

En los últimos tiempos $-\mathrm{y}$ según ciertos enfoques más emotivos que rigurosos- los escritores argentinos damos la impresión de no ser más individuos diversos, discutibles en tanto escritores, concientemente 
inmersos o no en nuestra realidad; un milagro ha borrado los matices; hoy somos una especie de abstracción que cabría dentro de una de estas dos categorías neoplatónicas: radicados en el exterior, lo que equivaldría a "condenados fatalmente a vivir lejos de la patria", o radicados en la Argentina, lo que equivaldría a "mártires o muertos en vida". (Exilio 3) [Énfasis en el original]

Haciendo la salvedad de que estas categorías así delineadas no se encuentran en el texto confrontado de Cortázar, la crítica a la emotividad como careciente de rigor -en este caso, de exactitud- y la asociación de un discurso social de denuncia con el neoplatonismo como corriente filosófica relativa a una mirada mística de la realidad, serán los cauces elegidos por la escritora para leer el artículo de la revista Eco.

Más adelante, describe que esa clasificación neoplatónica promueve la inacción, la parálisis, tanto en el exterior como en el país -parálisis que Cortázar advierte como síntoma (entre varios otros) en escritores exiliados y que se propone revertir a través de su artículo-. En la visión de Heker, es ese esquema el que inmoviliza y no una cierta realidad así vivida, así entendida y expresada conceptualmente. Al escribir estas primeras afirmaciones, la autora todavía no ha hecho mención a Cortázar, por lo que se supone que esa línea de análisis criticada es atribuida a alguien más que a él; luego, agrega que el artículo de Eco "contribuye -no intencionalmente, pero de manera decisiva- a este esquema" (3).

Heker reconoce que Cortázar es "uno de nuestros mayores escritores", que es querido por un "nosotros" que la incluye, que es siempre solidario aunque "negligente" con "nuestra realidad cultural" (3). En una nueva entrada hacia la presentación de la dupla emoción/exageración, agrega: "Ya que no se le puede atribuir mala fe, al menos puede suponérsele cierto apresuramiento, una necesidad a ultranza de hacer causa común con los exiliados aún a riesgo de dar una imagen maniquea de la realidad, valiéndose de recursos más pasionales que científicos." (3) En este caso, el campo léxico de la dupla referida incorpora la pasión en tanto 
emotividad exacerbada, y el apresuramiento en tanto exageración del ritmo. Cortázar "va demasiado rápido", es decir, no realiza un balance equilibrado de la realidad, presa de la pasión por respaldar a los exiliados externos e internos de la Argentina.

Valiosa resulta la aclaración de Angenot respecto al valor polémico de la pasión como movilizador de subjetividades "al lado de las pruebas racionales", para considerar los recursos de Cortázar en su polémica auténticamente asumida, la que tiene a "la Junta" como blanco y real antagonista: "El escritor puede hacer figurar lo que la antigua retórica llamaba las 'marcas Pasión'. Es una característica general de los discursos doxológicos el no poder satisfacerse con demostraciones en su racionalidad desnuda. La polémica debe no sólo aumentar la adhesión del auditorio sino también hacerlo salir de la apatía, incitarle a actuar". (Polémica, 10) [Énfasis en el original].

Si la dupla emoción/exageración ha sido aplicada críticamente a conceptos y modos de aproximarse al análisis de esa realidad, otro párrafo del texto de 1980 abarca también las frases adverbiales utilizadas por el escritor:

Ya refiriéndose a los últimos años, Cortázar habla de su exilio físico y su exilio cultural. En cuanto al exilio físico declara que si bien es muy posible que pudiera entrar a la Argentina sin dificultad, lo que sin duda no podría es volver a salir. Creo que los dos modos adverbiales son un poco excesivos: matemáticamente es probable que, si Cortázar decide venir, se presente algún tipo de dificultad, salvable o no; en cuanto a que "sin duda lo que no podría..." ese mecanismo de argumentar a priori se parece bastante al de la autocensura, algo que siempre hace más daño que la censura misma. (Heker, Exilio 4) [Énfasis en el original]

El señalamiento de los "adverbios excesivos" cumple la función de recordar la ausencia de Cortázar en el lugar de los hechos y, por tanto -se cree-, el déficit en su capacidad de encontrar los adverbios adecuados, en el preciso instante en que 
éste evalúa -con la información a su alcance, sin despojarse de una ironía muy propia de su universo literario y tal vez disonante frente a la gravedad de los crímenes que denuncia- las posibilidades de sobrevida una vez situado en el país. Pero por el trasdós del análisis gramatical, en el plano discursivo se desliza el desdén hacia la realidad de la matanza, la desaparición forzada de cientos de productores culturales, entre otros sujetos perseguidos, por mencionar ese segmento social que involucra esta crítica a Cortázar. "Dificultades salvables o no": las "no salvables" parecen no contener los crímenes dictatoriales, conocidos por la autora porque vivía en el país cuando éstos se cometían. "Y me explica, desde París, lo que ocurría entonces en la Argentina. Lamento que usted haya pasado por alto, Cortázar, que a fines del 78 yo estaba en la Argentina. Me privo de conmoverlo contándole porqué mi situación era menos confortable de lo que podría haber sido la suya acá." (Heker, Respuesta 7) [Énfasis en el original].

En efecto, respecto de esa realidad vivida solo emerge la censura -y Cortázar es un autor censurado en la época-. La autora que conoce la realidad porque la ha vivido, no ve riesgos en la visita al país del escritor argentino opositor a la dictadura más difundido internacionalmente. Por supuesto que hay un nivel de conciencia y voluntad en las palabras de Heker, pero como he señalado en los objetivos del presente artículo, en este caso no es allí donde busco detenerme, sino en las molduras que ha trabajado el terrorismo de Estado en buena parte de la sociedad argentina del momento y que, considero, la escritora expresa como discurso social. Es así como Heker subsume la preocupación del escritor por su vida en caso de entrar a la Argentina -preocupación que involucra el orden material del genocidioa la actitud de autocensura, que por su parte, remite a la realización simbólica del terror en quienes han tomado cuenta de la supresión de vidas, ya no solo de palabras o pensamientos, en la cotidianidad del país.

En la misma línea argumental, confronta a Cortázar con María Elena Walsh, quien el 16 de agosto de 1979 y residiendo en la Argentina, publicó el artículo “Desventuras en el País-Jardín-de-Infantes" en el suplemento Cultura y Nación del diario Clarín; insoslayable pieza crítica contra la censura dictatorial, que sin 
embargo no deja de exhibir las marcas del genocidio al pivotear su análisis sobre un aval explícito a lo actuado por la dictadura en la "dura guerra contra la subversión" (Desventuras, 15), aun cuando la autora tuviera la expectativa de que esto funcionara como una contraseña requerida para poder pasar sus afirmaciones críticas sobre otros aspectos tremebundos del régimen, e incluso poder darse la oportunidad de compararlo con la dictadura franquista o los enmascarados del $\mathrm{Ku}$ Klux Klan. El artículo de Walsh es merecedor de un estudio más amplio que el que aquí estamos en condiciones de abordar como espacio y como eje textual. Para nuestro análisis, solo tomaría la evidencia de un texto que sin carecer de coraje civil ni de lucidez, ni desdeñar la maestría de su escritura, se muestra habitado por el impacto del poder desaparecedor que ha campeado en las relaciones sociales contemporáneas a la imposición dictatorial. Es este núcleo de sentidos negados la desaparición forzada de personas no resulta un tema central en el artículo de Walsh (como tampoco en los de Heker ni en los de Castillo o Gregorich, por mencionar a intelectuales que han confrontado con Cortázar o con posiciones políticas afines a él, durante la dictadura)- el que rezuma entre otros ámbitos, en la producción cultural de la época, sobre todo a partir de 1980, cuando muchas palabras antes calladas comienzan a ser dichas en diversos medios públicos, sin aludir todavía al genocidio como tal. ${ }^{6}$

\footnotetext{
${ }^{6}$ Notablemente, Walsh capta el método de ese poder desaparecedor, aunque su objeto permanezca negado; en "Desventuras...", afirma: "Todos tenemos el lápiz roto y una descomunal goma de borrar ya incrustada en el cerebro. Pateamos y lloramos hasta formar un inmenso río de mocos que va a dar a la mar de lágrimas y sangre que supimos conseguir en esta castigadora tierra." (Desventuras 18). En el mismo año 1979 publica en el diario La Nación, "Complicidad de la víctima", una poco concesiva mirada sobre las "negociaciones" cotidianas bajo un régimen de oprobio: "Por eso permanezco/ fiel a iniquidades y censores./ Al fin y al cabo me porté bien,/ supe negociar/ mi pálida y frágil sobrevivencia" (Poemas 177). Sobre la claridad respecto a que lo que estaba sucediendo en la Argentina dictatorial configuraba un genocidio, preciso es señalar que ya para enero de 1981, las Madres de Plaza de Mayo (MPM) -que llevaban entonces casi cuatro años de presencia pública y colectiva en la Plaza de Mayo- referían el término en sus documentos, como realidad negada por los dictadores, a la par que exigían "aparición con vida de los detenidosdesparecidos", como expresión de un deseo irrenunciable y como forma de aludir a la índole clandestina y estatal de las desapariciones forzadas. V. el discurso de Élida Galetti (MPM) en el Primer Congreso de la Federación Latinoamericana de Asociaciones de Familiares de Detenidos y Desaparecidos (FEDEFAM), realizado en Caracas, en enero de 1981 (Oria).
} 
Desde la perspectiva de Heker, Cortázar es quien piensa en marcos de autocensura y, en tanto permanece en el exterior, no le es concedida legitimidad a su voz crítica frente a la Junta. Una cita de Avellaneda de su libro Censura, autoritarismo y cultura: Argentina 1960-1983 nos permitirá vincular más precisamente estos marcos de terror y autocensura circulantes en la sociedad bajo el régimen dictatorial:

La historia de la cultura es también una historia de la censura, un registro de negociaciones solapadas o explícitas entre los productos culturales y el control del Estado. No hay sociedad que se evada de estas relaciones peligrosas, de estas transacciones entre el Poder y el Texto, entre el aparato del Estado y la variada serie de los discursos culturales. [...] Examinar el desarrollo de la censura en una cultura y en una época determinada no es pues reclamar para estas últimas un rasgo distintivo, sino más bien practicar en ellas un corte longitudinal que revele el modo en que ambas cultura y época, texto y realidad- se articulan entre sí, y, a su vez, con ese otro tipo de discurso que se llama censura. (7)

Para retomar un enfoque que puede tender a diluirse en la trama del presente texto al tener que remitirnos a las firmas autorales para su exposición, lo que nos importa de esta tópica "polémica" revisitada hoy, cerca de cuarenta años después de producida, son los discursos sociales que expresan. Exactamente, el modo en que ambas -cultura y época, texto y realidad- se articulan entre sí, y, a su vez, "con ese otro tipo de discurso que se llama censura”. En ese sentido, Heker vehiculiza tempranamente un discurso que cobrará más fuerza en la posdictadura y, con intermitencias, se dejará oír hasta el presente. Cuando considera la situación de censura en América Latina como “el ámbito en que, salvo épocas excepcionales, han creado y opinado todos los grandes escritores rebeldes en sus países" (Exilio 4), algo de la cultura y la época, el texto y la realidad se cuelan ahí de un modo que bascula entre la conciencia (y por lo tanto la autocensura) y el vacío conceptual 
promovido por la acción desaparecedora en la trama social. Esto es, la dictadura de Videla no rompe ese supuesto continuum hostil en que -dice Heker- crean los grandes intelectuales latinoamericanos. Argentina, 1976 en adelante, es un país "cualquiera", uno como cualquier otro (estas frases aparecen reiteradamente en los artículos de la escritora para esta serie): la secundarización, cuando no la negación, por ausencia en su texto, de "la causa esencial de ese exilio" (Cortázar, Carta 4) corre por su laberinto invisible, en plena dictadura, y produce sus discursos; perdurables, por cierto. Pensar lo contrario, como lo hace Cortázar-que no se trata de una dictadura más, que hay genocidio cultural, exilio externo e interno político y de violentas características que se expande mucho más allá que sobre las personas así avasalladas- es incurrir en "exageraciones".

La misma negación asoma en el primer artículo de Heker cuando considera los motivos de Cortázar como una "enumeración patética" y afirma que lo que más aqueja al escritor local es la situación económica. El "patetismo", la "imprecisión", la "demagogia lírica" representan otras tantas formas de aludir a la, así considerada, deficiente estrategia cortazariana de la emoción y la exageración. Además de esa negación, manifiesta en las diversas descalificaciones de los modos de la emoción, también figura, al citar un párrafo de "América Latina, exilio y literatura", la negación por omisión directa de la frase en la que resulta clave la expresión "la gente desaparece". Cortázar escribe:

Un exiliado es casi siempre un expulsado, y ése no era mi caso hasta hace poco. Quiero aclarar que no he sido objeto de ninguna medida oficial en ese sentido, y es muy posible que si quisiera viajar a la Argentina podría entrar en ella sin dificultad; lo que sin duda no podría es volver a salir, aunque desde luego la junta militar no reconocería ninguna responsabilidad en lo que pudiera sucederme; es bien sabido que en la Argentina la gente desaparece sin que, oficialmente, se tenga noticia de lo que ocurre. (11) 
Pero en El Ornitorrinco de 1980, la cita se suspende al final de la frase "lo que sin duda no podría es volver a salir", para retornar, tras los paréntesis y los puntos suspensivos, con un fragmento posterior del texto de Cortázar que refiere a "mi reciente exilio cultural" (América Latina 3). Se dirá que es así porque ése, el impugnado exilio físico y cultural de Cortázar, pretende ser el tema de la crítica de Heker. No afirmo otra idea. Precisamente, el tema elegido para "polemizar" ratifica el alcance del genocidio cultural, el orden desaparecedor impuesto sobre los cuerpos, las relaciones sociales, la intimidad de la vida cotidiana, tanto como sobre los problemas a debatir por lo/as intelectuales.

Pasados algunos años de las fechas en que este "imperfecto diálogo", al decir de Cortázar (Carta 3), se llevara a cabo, el narrador y poeta uruguayo Enrique Estrázulas, motivado por la presencia del escritor en Buenos Aires, y el promisorio marco del fin de la dictadura argentina (1983), escribe:

Sus declaraciones políticas - esta vez ubicadas e inteligentes- no hablaron de "genocidio cultural" y otras formas de la exageración que en alguna instancia, marcaron la voz de centellantes polémicas con algunos escritores que permanecieron en la Argentina durante el sangriento período que, aparentemente, ha culminado con el saludable retorno a la vida institucional. (13)

En 1983 y para vastos sectores sociales locales y regionales aun no era posible pensar lo ocurrido en Argentina como un plan sistemático de exterminio, un genocidio perpetrado con el arma de la desaparición forzada de personas como principal factor de desarticulación social, cultural, política y de las subjetividades individuales y colectivas. Se trata del imperio subrepticio de una huella social de impredecibles alcances, tanto para la época como en la actualidad, sin que por ello dejemos de considerar los cambios de contexto, los avances comunitarios en la capacidad de develar lo oculto, de reflexionar sobre sus diversos modos de 
implicancia y responsabilidad, de hacer justicia para con tales crímenes contrarios a la humanidad.

La trama discursiva de esta polémica elidida, que a la vez precipitó escenas de confrontación verbal perdurables en el tiempo, ha ido modulando de diversas maneras y a través de distintos sujetos sociales, políticos, intelectuales. Desde un universo ideológico muy diferente al sustentado por Heker, Castillo, el mismo Estrázulas, en la Argentina reciente se ha configurado un "negacionismo estatal" que recae en el tópico de la "exageración" para diluir las memorias construidas en torno al terrorismo de Estado. La subestimación de las cifras del genocidio ha sido una de sus estrategias. Sin originalidad: esa manera de negar lo sucedido se verifica, como una constante, en otros marcos situacionales posgenocidas (Thus). Sin embargo, el negacionismo no es idéntico a la negación del genocidio aquí mencionada, por más que hallemos en ellos recursos similares. La primera de las prácticas comporta una deliberación política en el borramiento del pasado y un propósito de deslegitimación de actores sociales, políticos y culturales en el presente, articulados a una estrategia de dominación.

La negación a que me he referido en este trabajo asume tanto las características de una imposición a través del terror de Estado, como las de un acatamiento, muchas veces imperceptible en sus recorridos sociales y subjetivos. Cuando determinadas subjetividades personales y colectivas son colocadas en trama histórica, relacional, respecto de otras intervenciones también personales y sociales, algunos de estos vacíos, ocultamientos y distorsiones conceptuales respecto de la realidad vivida, pueden emerger con cierta claridad. Por eso no es ocioso consignar voces y prácticas alternativas a las de la omisión, sea por causa del terror o la complacencia, como las que ha expresado el movimiento de las Madres de Plaza de Mayo en el país o Cortázar fuera de él, entre otras voces y agencias presentes en ambas espacialidades.

Tales efectos de las desapariciones en la sociedad configuran un proceso complejo, continuo, que involucra a múltiples actores y se relanza en la contemporaneidad, entendida ésta en el sentido de Agamben, es decir, como aquel 
desfasaje del tiempo propio que permite, al igual que sucede con las estrellas del universo, "percibir en la oscuridad del presente esa luz que trata de alcanzarnos y no puede" (Qué 23). Desde esta perspectiva, el negacionismo de hoy estaba ya en la contemporaneidad de la dictadura porque formaba parte de su plan de exterminio y de su condición de impunidad. Simultáneamente, el poder desaparecedor liberado por ese plan genocida sembró -con diferente suerte y resultados según grupos e individuos, desde luego-, la negación y el vacío en la sociedad. Así es como la explícita emergencia en el presente de aquel negacionismo, también estatal, vuelve su haz de oscuridad sobre aquellos años, de modo que estas tinieblas "iluminan" aquellas otras.

\section{Consideraciones finales}

La propuesta de recorrer una vez más la denominada "polémica" entre Heker y Cortázar fue concebida como un modo de acercarnos a componentes no siempre recuperados en las sucesivas visitas realizadas por la crítica cultural en los años que distan entre aquellos intercambios críticos y la actualidad. Las condiciones en que tal "polémica" pretendió desarrollarse han sido un marco fundamental para el análisis propuesto y un factor clave para considerarla elidida. Debate retaceado por Cortázar habida cuenta de un poder -el de la Junta- que delimitaba en sentido político las nuevas condiciones de posibilidad de las vidas, las muertes, la creación, las resistencias; y retaceado también frente a una intelectual de estrecho conocimiento previo que le proponía debatir aspectos de su escritura elidiendo, a su vez, aquello que se presentaba como principal y definitorio de una época: el genocidio cultural en Argentina durante la dictadura de 1976. Una tercera elisión buscamos hacer visible, la de la imposibilidad de una real polémica en el contexto mencionado, determinada por el quiebre del contrato de lectura vigente entre la intelectualidad latinoamericana con anterioridad a las imposiciones dictatoriales, particularmente las de los años '70 del siglo XX.

La trama textual previa en la que se inscriben los intercambios de $1980 \mathrm{y}$ 1981, abre un campo de investigación que continuaremos en nuevas etapas de 
trabajo, y nos ha posibilitado aquí, insertar al mismo tiempo que rever críticamente, las continuidades y rupturas discursivas planteadas a la intelectualidad antidictatorial en el contexto del terrorismo de Estado.

A través de un análisis de los códigos de identificación recurridos y las rendiciones promovidas por la autocensura, presentes en los intercambios textuales del período en revisión para publicaciones realizadas en el país, intentamos poner en evidencia la serie de negaciones y vacíos léxicos producidos en cierta discursividad intelectual, que en la pretensión de una vía polémica, deja expuestas las marcas del genocidio, aun cuando cree librar una contienda significativa de la resistencia cultural. Las nociones de emoción y exageración, que dan armado a la secuencia crítica de Heker frente a Cortázar, nos permitieron asomar al efecto secundarizante de los crímenes dictatoriales verificado en la tensa relación, para el caso, entre la serie literaria y la serie social, donde la primera elide y trastorna aspectos fundamentales de la segunda.

Parte de estas reflexiones han sido estimuladas por el regreso con nuevos ropajes de un discurso negacionista de viejo cuño en la sociedad argentina, avalado por poderes dominantes de similar antigüedad y actualidad. A la par, en los nuevos contextos del rico proceso de Memoria, Verdad y Justicia argentino que no cesa de reponer la dimensión del genocidio y la capacidad de respuesta del movimiento de derechos humanos, Cortázar vuelve a pronunciarse, desde sus escritos que buscaban apoyar "todas las formas inteligentes de combate" (Exilio 13), con la emoción de su libertad. 


\section{Bibliografía}

Agamben, Giorgio. “¿Qué es lo contemporáneo?”. Desnudez. Buenos Aires: Adriana Hidalgo, 2011. 17-29. . Estado de excepción. Buenos Aires: Adriana Hidalgo, 2014.

Angenot, Marc. El discurso social. Los límites históricos de lo pensable y lo decible. Buenos Aires: Siglo XXI, 2010. . “1889: Por qué y cómo escribí este libro -y algunos otros”. Cuadernos LIRICO. (2016). https://doi.org/10.4000/lirico.3176. 23 agosto 2020. . "Polémica/panfleto/sátira. Tesis generales". La parole pamphlétaire. Tipologie de discours modernes. Parte II. Cap.I. París: Payot, 1995. 1-12. [Traducción de Aurelie Bartolo y Paul Nitsche. Revisión de Beatriz Colombi. Buenos Aires: FFyL-UBA, 2006.]

Avellaneda, Andrés. El habla de la ideología. Buenos Aires: EUDEBA, 1983. . Censura, autoritarismo y cultura: Argentina 1960-1983. Buenos Aires: CEAL, 1986.

Bayer, Osvaldo. "Pequeño recordatorio para un país sin memoria". Rebeldía y esperanza. Buenos Aires: Ediciones B-Grupo Editorial Z, 1993. 223-253.

Blanco, Mariela. "Espacios de definición de la poesía de los '60. El grillo de papel y El escarabajo de oro". Calabrese, E. y Aymara del Llano, editoras. Animales fabulosos. Las revistas de Abelardo Castillo. Mar del Plata: Martin y UNMdP, 2006. https://www.ahira.com.ar/wpcontent/uploads/2018/07/BlancoEspaciosde definiciondelapoesia.pdf. 21 septiembre 2019.

Calabrese, Elisa. "Las revistas de Abelardo Castillo". Revista del Centro Hispanoamericano 17 (2005-2006): 39-57.

Carbone, Alberto. "Julio Cortázar: 'Mi ametralladora es la literatura'”. Crisis 2 (1973): 10-15.

CONADEP. Nunca más. Informe de la Comisión Nacional sobre la desaparición de personas. Buenos Aires: EUDEBA. 1985.

Conti, Haroldo. "Cuando enmudezcan todas las voces". La Opinión Cultural, 8 dic. 1974: 4

Cortázar, Julio. "América Latina: exilio y literatura". Argentina: Años de alambradas culturales. Barcelona: Muchnik, 1984.16-25. ."Carta a una escritora argentina". El Ornitorrinco 10 (1981): 3-4.

Diego, José Luis de. “¿Quién de nosotros escribirá el Facundo?” Intelectuales y escritores en Argentina (1970-1986). La Plata: Al Margen, 2004.

Duhalde, Eduardo Luis. El Estado terrorista argentino. Quince años después, una mirada crítica. Buenos Aires: EUDEBA, 1999.

Eagleton, Terry. Una introducción a la teoría literaria. Madrid: Fondo de Cultura Económica, 1993.

Estrázulas, Enrique. “Margen de error para Cortázar”. El Día, 10-16 dic.1983:13. [Archivo Federico Barea]. 
Feierstein, Daniel. El genocidio como práctica social. Entre el nazismo y la experiencia argentina. Buenos Aires: FCE, 2007.

Ferrero, Adrián. "Exilio poético y exilio político: la polémica entre Liliana Heker y Julio Cortázar en la revista cultural El Ornitorrinco". Questión 1/16 (2007): $1-8$

https://perio.unlp.edu.ar/ojs/index.php/question/article/view/442. 21 septiembre 2019.

Gatti, Gabriel. Identidades desaparecidas. Peleas por el sentido en los mundos de la desaparición forzada. Buenos Aires: Prometeo, 2011.

Gilman, Claudia. Entre la pluma y el fusil. Debates y dilemas del escritor revolucionario en América Latina. Buenos Aires: Siglo XXI, 2003.

Giordano, Alberto. "Cortázar y la denegación de la polémica". Punto de Vista 77 (2003): 37-42.

Heker, Liliana. "Exilio y literatura. Polémica con Julio Cortázar". El Ornitorrinco 7 (1980): 3-5.

. "Respuesta de Liliana Heker". El Ornitorrinco 10 (1981): 4-7.

Jensen, Silvina. "Vientos de polémica en Cataluña: los debates entre 'los de adentro' y 'los de afuera' de la Argentina de la última dictadura militar". Revista HMiC 3 (2005): 189-209.

Maingueneau, Dominique. Introducción a los métodos de análisis del discurso. Problemas y perspectivas. Ciudad: Hachette, 1980.

ONU. Convención Internacional para la protección de todas las personas contra las Desapariciones Forzadas. Nueva York: ACNUDH (2008). https://www.ohchr.org/SP/ProfessionalInterest/Pages/ConventionCED.as px. 14 agosto 2020.

Oria, Piera P. De la casa a la plaza. Buenos Aires: Nueva América, 1987.

Pollak, Michael. Memoria, olvido, silencio. La producción social de identidades frente a situaciones límite. La Plata: Al Margen, 2006.

Romano, Eduardo. "Revistas argentinas del compromiso sartreano". Cuadernos Hispanoamericanos 430 (1986):164-179.

Saítta, Sylvia. "Polémicas estéticas y apuestas literarias en las revistas de Abelardo Castillo". Verónica Delgado y Geraldine Rogers, editoras. Tiempos de papel. Publicaciones periódicas argentinas (siglos XIX y $X X$ ). La Plata: UNLP FHCE, 2016. 304-317.

Sosnowski, Saúl. Represión y reconstrucción de una cultura: el caso argentino. Buenos Aires: EUDEBA, 1988.

Terán, Oscar. Nuestros años sesentas: la formación de una nueva izquierda intelectual en la Argentina. Buenos Aires: Puntosur, 1991.

Thus, Valeria. "Los desaparecidos según Macri. ¿Encarna la Argentina un negacionismo estatal ?". Espacios de Crítica y Producción 53 (2017): 117-135.

Viñas, David. De Sarmiento a Cortázar. Buenos Aires: Siglo XX, 1974.

Walsh, María E. "Desventuras en el País-Jardín-de-Infantes". Desventuras en el País-Jardin-de-Infantes. Buenos Aires: Sudamericana, 1993. 13-18. 
. "Complicidad de la víctima". Poemas y canciones. Buenos Aires:

Alfaguara, 2014. 175-177.

\section{Fuentes audiovisuales}

Chao, Ramón. "Julio Cortázar: escapismo y búsqueda de la identidad”. Radio Francia Internacional (1978).

https://soundcloud.com/radiofranceinternationale/julio-cortazarescapismo-y-busqueda-de-identidad 21 agosto 2019.

Lejtman, Román. "Centro Piloto. Massera en París". Documenta (2 julio 2006). https://www.youtube.com/watch?v=u-Pjasch09I. 22 agosto 2019.

Montes Bradley, Edgardo. "Cortázar: apuntes para un documental". Contrakultura Films (2002). https://vimeo.com/108755591 . 5 diciembre 2019. 